\title{
Some Remarks about the Deployment of Floating PV
}

\section{Systems in Brazil}

\author{
Marco Antonio Esteves Galdino and Marta Maria de Almeida Olivieri \\ Cepel-Electric Power Research Center (Centro de Pesquisas de Energia Elétrica), Eletrobras, Rio de Janeiro, 21941-911, Brazil
}

\begin{abstract}
Floating photovoltaic systems installed in water bodies such as natural lakes or dams reservoirs, have attracted increased worldwide attention since 2011 and have already been deployed in several countries, including Japan, South Korea and USA. In Brazil, pilot-projects were announced in the reservoirs of hydroelectric power plants of Balbina (State of Amazonas) and Sobradinho (State of Bahia). Several advantages, not necessarily valid in Brazil, are mentioned for deploying this kind of technology, such as an increase in energy generation, reduction of water losses through evaporation, low environmental impact, no occupation of land etc. In this article, several of these allegations are analyzed preliminarily under the Brazilian point of view, and relevant considerations are presented. It is concluded that the technical and economic advantages of floating photovoltaic systems are not yet clear in Brazil and that pilot projects, such as those under way, should be used to clarify several important aspects related to them.
\end{abstract}

Key words: Floating PV systems, photovoltaics, dam reservoirs.

\section{Introduction}

Since 2011, experimental floating PVPs (photovoltaic plants) have been deployed around the world, in which PV arrays are mounted floating on water bodies as natural lakes or artificial water reservoirs built for different purposes.

Such experiments have been reported in a number of countries, including Japan, South Korea and USA. To the present, Japan can be considered the country with the most technological expertise in this field, regarding the number of existing floating PVPs in the country. Some authors have called these plants "floatovoltaics" installations.

A plant with an installed capacity of 2.9 MWp, inaugurated in late March 2015 by the company Kyocera Solar, was reported as the largest existing of this type [1] at the time. This plant (Fig. 1) is located in Hyogo Prefecture, Kato city, Southwest of Honshu Island (main island of Japan), and is divided into two subarrays, floating on the lakes of Nishihira and

Corresponding author: Marco Antonio Esteves Galdino, M.Sc., research fields: photovoltaics, solar energy, solar radiation.
Higashihira, with 1.7 MWp and 1.2 MWp, respectively. The assembly of the PVP began in September 2014, so that the installation works took 7 months.

An annual generation of 3,300 MWh [3] is expected to be supplied to the utility Kansai Electric Power, which means an annual capacity factor (fc) of $\sim 13 \%$. The company Kyocera Solar was the supplier of photovoltaic modules (11,256 Kyocera modules of 255 Wp) and also installed, operates and maintains the plant.

For the assembly of the PV arrays, floating structures called "Hydrelio (C)" made of high density polyethylene-HDPE, patented (and supplied) by the French company Ciel et Terre [4] are adopted. The polymeric material is said to be the same used in marine signaling buoys and the assembly does not use metal parts, being made by means of fittings only.

In December 2014 Kyocera announced [5] the construction of a floating PVP of 13.4 MWp at the Yamakura Dam Reservoir, in Chiba Municipality (near Tokyo), occupying an area of 180,000 $\mathrm{m}^{2}$ and an expected generation of 15,635 MWh/year (annual fc: 13.3\%) to be sold to TEPCO (Tokyo Electric Power Co). Kyocera also had plans to build 30 floating PVPs 


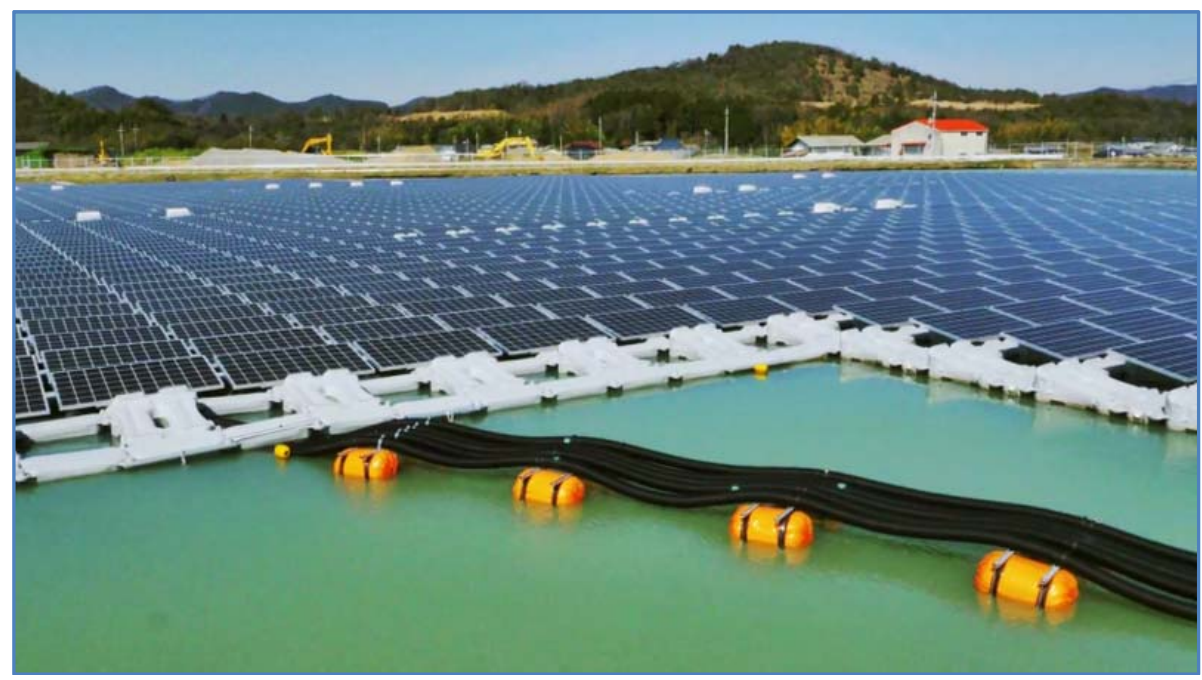

Fig. 1 Floating PV system in Hyogo-Japan (Source: Ref. [2]).

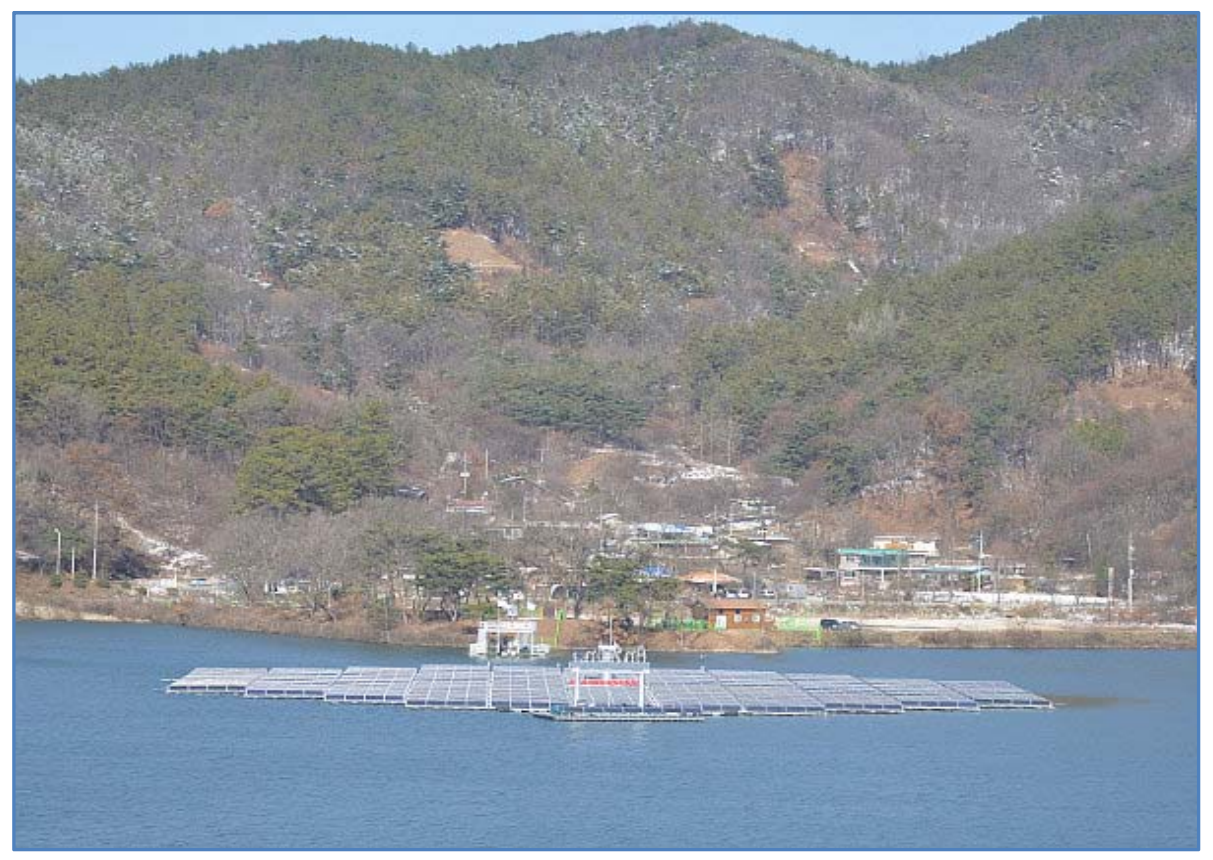

Fig. 2 Floating tracking PV system in Korea (Source: SolarPark Korea).

in Japan from 2015 to 2016.

South Korea also has accumulated experience in floating PVPs, having installed a $465 \mathrm{kWp}$ (occupied area of 8,000 $\mathrm{m}^{2}$ ) experimental system in 2014 which was said to be the only floating plant with solar tracking [6] at that time, and whose efficiency would be $22 \%$ higher than that of an equivalent plant mounted on the ground (Fig. 2).

In the USA, which has already several smaller floating PV installations, a 12.5 MWp plant in the State of California was announced, following a business format in which the lakes will be used under a grant by the owner to the generating company, through a leasing mechanism [7].

Fig. 3 shows the diagram of one possible configuration for a floating PV plant and its main components.

- PV array: there are already available PV modules specially designed for floating PV arrays [8], with improved waterproof characteristics; 


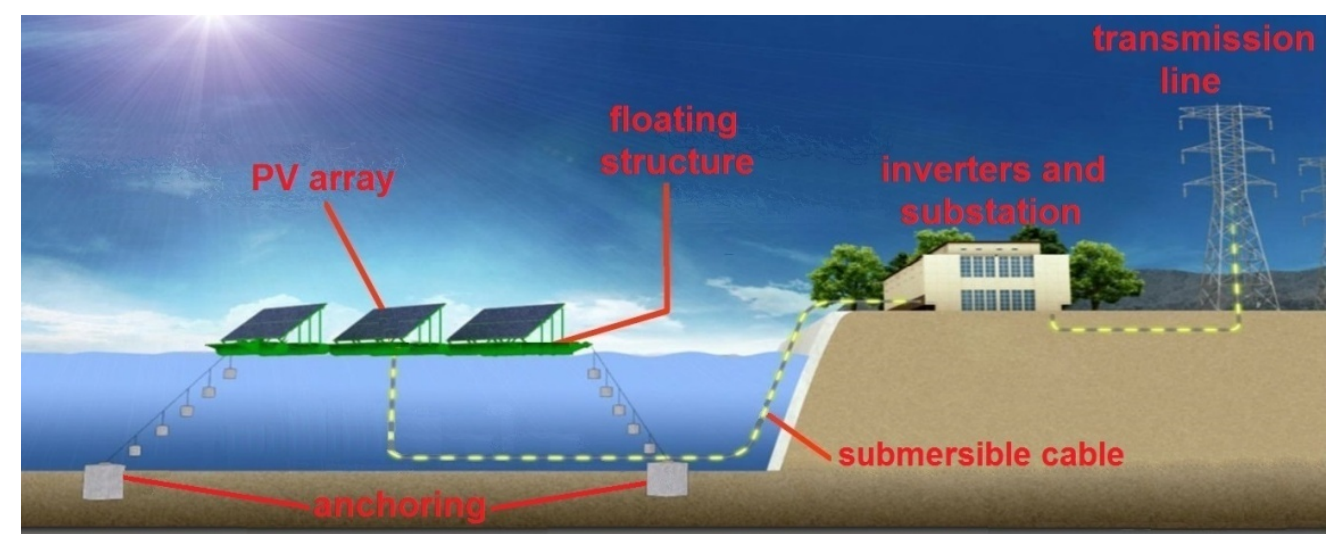

Fig. 3 Diagram of a floating PV plant (Source: adapted from Ref. [8]).

- Floating Structure: must be specified in order to resist the wind speed, wave height and water velocity (current) expected at the site;

- Achoring: must be designed to cope with the expected variation in the water level, as well as with the forces due to wind, waves, and current;

- Cables: submersible cables shall be used, as well as watertight junction boxes etc.

- Inverters and substation: conventional installation, comprising the grid-connected inverters, switchgear, transformers, protection etc.

\section{Floating PV Plants in Brazil}

In Brazil, pilot projects of $5 \mathrm{MWp}$ floating PV plants in the lakes of the hydroelectric power plants of Sobradinho (State of Bahia, Northeast region of Brazil) and Balbina (State of Amazonas, North region) were announced [9], to be started in 2015, by the federal utility companies Chesf and Eletronorte, respectively, attracting international interest $[10,11]$.

The first floating PV installation in Brazil was inaugurated on March, 4th, 2016 in the Balbina reservoir, comprising an area of only $60 \mathrm{~m}^{2}$, and is considered as an initial phase of the pilot project for deployment of floating PV in the country.

Another floating PV installation was put into operation in August, 2016 [12], comprising $25 \mathrm{kWp}$ of c-Si modules and $25 \mathrm{kWp}$ of thin film modules, occupying approximately $500 \mathrm{~m}^{2}$, in the reservoir of the hydro power plant of Porto Primavera (State of São
Paulo, Southeast region of Brazil). This is an independent installation and is not a part of the above mentioned pilot project.

\section{Technical Advantages of Floating PV Plants}

Several technical advantages that have been attributed in literature to floating PV systems are listed below and it is shown that some of them need better investigation und understanding.

(1) The evaporative cooling of PV modules and cables caused by the water body increases the efficiency of the system

An analysis of the performance of floating $100 \mathrm{kWp}$ and $500 \mathrm{kWp}$ photovoltaic systems installed by the company K-Water (Korean Water Resources Corporation) at the Hapcheon dam reservoir was performed by Ref. [13], comparing the performance of these systems with a conventional $1 \mathrm{MWp}$ photovoltaic plant mounted on the ground (located about $60 \mathrm{~km}$ south of Hapcheon). This study indicates that the efficiency of the floating system is $11 \%$ higher than the conventional one since the floating systems operate at a lower temperature than the ground system, because of the evaporative cooling provided by the reservoir.

However, an analysis from the economic point of view was not made, in order to evaluate if the economic gain with the improvement of performance surpasses the higher cost of the floating system.

It should be remarked that the evaporative cooling is 
a function of the Wet Bulb Temperature (Twb) of the site, in turn dependent on the ambient temperature and relative humidity, as well as the wind speed. In the Brazilian case, the $11 \%$ increase in efficiency noticed in Korea is not necessarily valid since, being a tropical region, and given the country size and geographical diversity, its environmental conditions are not only very different from Korea but also different in each region. In the Brazilian pilot projects, it can be forecasted that the floating PV plant to be installed at the Sobradinho reservoir, located in a place with low relative humidity (semi-arid region) and high wind speed (yearly average wind speed of $5,6 \mathrm{~m} / \mathrm{s}$ at a height of $50 \mathrm{~m}$ ), could benefit greatly from the cooling effect. However, in the case of Balbina reservoir, this effect will provide a much more limited increase in the efficiency of the floating PV system, since it is located in a region (Amazon region) with high air humidity and low wind speed (yearly average wind speed of 2,96 m/s at a height of $50 \mathrm{~m})$.

(2) The floating structure reduces the evaporation of the free surface of the water, keeping the volume of stored water

The shading provided by the floating structure reduces the incidence of solar radiation in water, and therefore its temperature. In addition, the presence of the floating PV array covering the free surface of the water also reduces the effect of the wind on this surface. These two factors together contribute to the reduction of water evaporation. This type of benefit, however, is very difficult to quantify, i.e. it is very difficult to determine how much water would be lost without the floating PV array.

It should also be mentioned that this effect is physically conflicting with the previous one, that is, the less evaporation in the reservoir, the lower the evaporative cooling caused by the water body and the lower the efficiency increase of the photovoltaic array.

The net evaporation rate of the Balbina reservoir is only $122 \mathrm{~mm} / \mathrm{m}^{2}$.year, while for the Sobradinho reservoir it reaches $1,946 \mathrm{~mm} / \mathrm{m}^{2}$.year [14], so demonstrating that the advantages of reducing losses and increasing efficiency by evaporative cooling in Balbina will be clearly much lower than in Sobradinho.

(3) The floating PV array reduces algae growth

It is reasonable to assume that the shading provided by the PV array, reducing the incidence of solar radiation in the water, also reduces the growth of algae (phytoplankton). This effect has also not yet been quantified, and certainly also depends on the fraction of the area of water surface covered by the PV array. Supposedly it could be beneficial for lakes with an environmental problem called eutrophication, which is an anomalous algae (and other aquatic plants) growth, sometimes referred to as "green tide", caused by the presence of excess of nutrients (mainly Nitrogen and Phosphorus compounds) dissolved in the water. Such an overload of nutrients can be the result of human activities (agriculture etc.). This is surely not the case of the lakes of Sobradinho and Balbina in Brazil.

On the other hand, light blocking and reduction of algae growth may constitute a possible significant environmental impact of the PV plant on the natural ecosystem of the reservoir.

(4) The floating structure reduces the formation of waves and, thus, the erosion of the banks of the reservoir

As already mentioned, in principle, the presence of the floating structure reduces the effect of the wind on the free surface of the water, as well as the consequent formation of waves and thus the wave erosion in the banks. The result, again, depends greatly on the fraction of the area occupied by the PV array, and its quantification as well as understanding of its actual benefit is very difficult to evaluate.

(5) A floating PV system installed in the reservoir of a hydroelectric power plant saves water in that reservoir, replacing part of its generation

Some authors say that a form of combined operation of the PV power plant with the hydroelectric plant would save water, as it could generate less hydro power during the day, being complemented by the PV 
generation. However, to do so, the installed power required for the PV plant should be of an order of magnitude comparable with the hydro power plant, which in Brazilian pilot projects should mean at least dozens of MW (Sobradinho: 1,050 MW and Balbina: $250 \mathrm{MW}$ ), what is not yet considered feasible.

Even if such big floating PV plants could be built in Brazil, the combined generation is not simple to implement in practice, since the dynamics of variation of PV generation occurs in intervals of seconds (cloud passages), and cannot be compensated by the generation of the hydro power plant, whose time constant is much larger. This creates an operational difficulty for the maintenance of a certain constant value of generation, which is pre-established in a mandatory schedule in Brazil. In order to overcome this, energy storage (Li-ion batteries, $\mathrm{H}_{2}$ etc.) could be associated to the PV plant, but this would add complexity to the system and increase significantly its cost. Therefore, the combined operation can still be considered a topic for R\&D.

In fact, conceptually, any PV generation connected to the grid in Brazil contributes to reducing the overall hydraulic generation (the base generation in Brazil is hydraulic) and, thus, to saving water in the reservoirs, but this does not apply to a specific installation, only to the national electrical system as a whole. In a combined installation of this type (floating PV plant and hydro plant), it is conceptually more correct to consider that the PV plant as an additional generation, is practically independent from the hydro generation.

(6) A floating PV system installed in the reservoir of a hydro power plant does not require investment in transmission infrastructure, since the existing infrastructure can be shared

According to the Brazilian technical regulations, high voltage transformers must be able to withstand daily overloads of $120 \%$ for 4 hours and $140 \%$ for 30 minutes. Therefore, in a preliminary analysis, if the power of the floating PV plant is less than $40 \%$ of the hydro power plant, then the infrastructure (transmission line, substation, transformers) can effectively be shared, since the PV system operating in tropical conditions, even considering the evaporative cooling, would not operate at its rated power for a daily period greater than 30 minutes.

This can be considered the most important advantage of floating PV installations in the reservoirs of hydro power plants in Brazil, causing a significant cost reduction.

The possibility of using the existing infrastructure for PV plants with installed power beyond this $40 \%$ limit must be evaluated specifically in each case. It depends on the ratio of the installed power of the PV plant and the hydro plant, and mainly on the operating regime of the hydro power plant.

For example, in the case of a hydro plant with a small reservoir and a significant amount of PV power, and in which the wet period (rain season) coincides with the maximum solar radiation period, the capacity of the existing transmission line and transformers may not be enough for the simultaneous operation of both plants at full capacity. This would limit the economic benefit or require extra investment in the transmission infrastructure. On the other hand, even in this case, the advantage of sharing may exist if there is a complementarity behavior between the wet period and the incidence of solar radiation at the site.

In the case of Balbina plant, for instance, it can be noticed that there is a coincidence between the operating regime of the hydro plant and the distribution of solar irradiation throughout the year, as shown in Fig. 4. So, if the installed floating PV power in Balbina is beyond the $40 \%$ limit, then investment in the transmission infrastructure could be necessary.

(7) The fact that the floating system does not use a land area is a great economic advantage

In the case of Japan, the fact that the floating PV plant does not use land areas is generally cited as an important economic advantage [17], due to the restricted availability and high cost of land in the country. In Korea and in the USA, this argument also 
seems to be valid. In the case of Brazil, however, this type of advantage is, in general, much less important and should be subject of a specific economic analysis.

(8) The reflectivity (albedo) of the water increases the incidence of radiation in the PV array and, therefore, its energy generation

Fig. 5 shows the specular reflectivity of the water (albedo) for direct radiation as a function of the angle

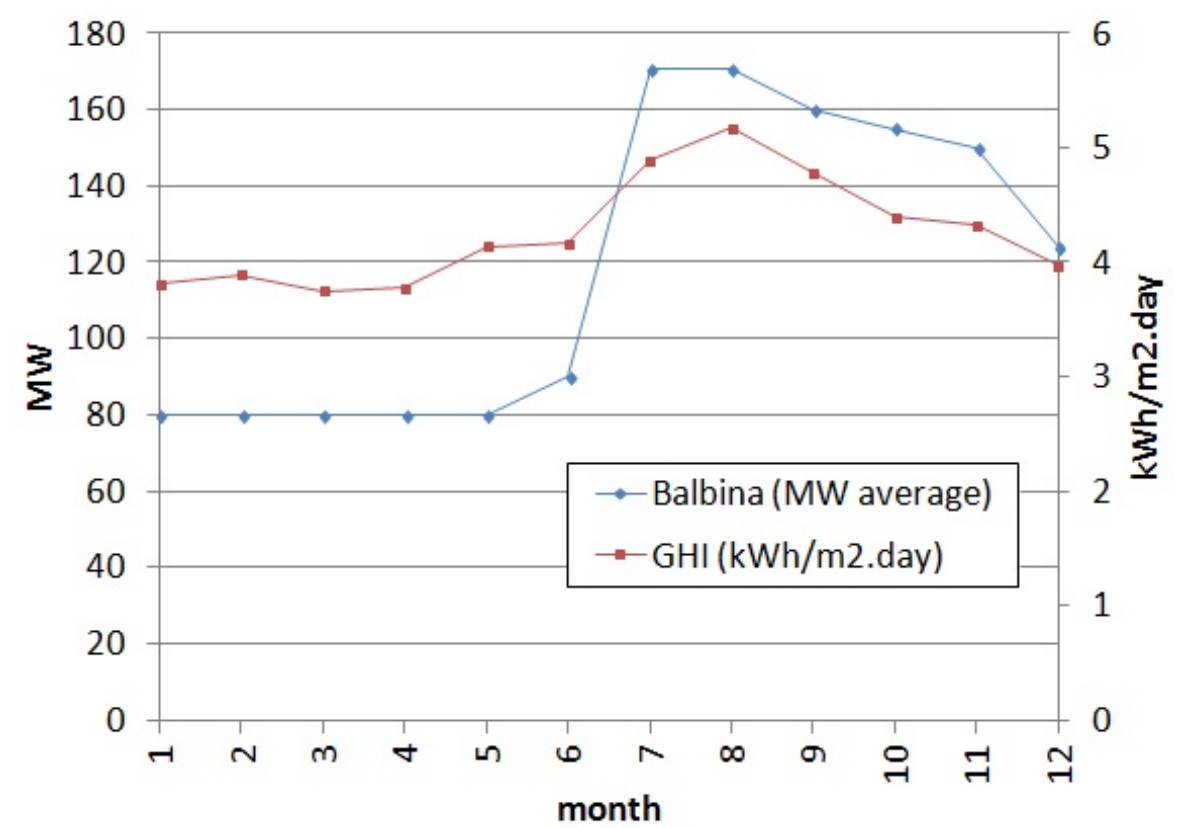

Fig. 4 Operating regime of Balbina hydro power plant and global solar irradiation on horizontal plane (GHI) throughout the year at the site. The energy generation data from Balbina refers to monthly averages for the year 2012 according to the source [15] and the solar irradiation corresponds to daily monthly averages available at the solar radiation database of Cepel [16] (standard year).

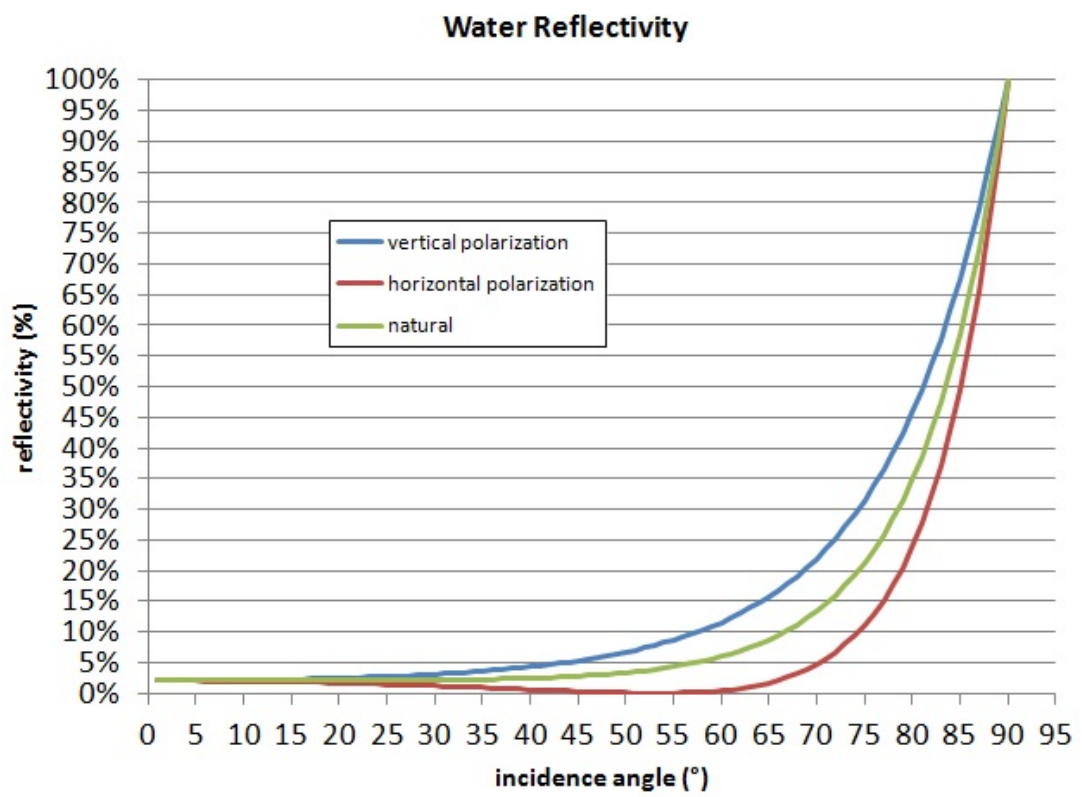

Fig. 5 Albedo of water for the incidence of direct solar radiation, as a function of the angle of incidence (in relation to normal incidence $0^{\circ}$ ), for clean water (without suspended material) and still water surface (no ripple at the surface). The bottom curve (red line) refers to horizontally polarized light and the upper curve (blue line ) to vertically polarized light. The average line curve (green color) is considered representative of natural solar radiation. (the graphic was made using Fresnel equations for refraction and reflection) 
of incidence, where one can notice that, for incidence angles in the range of $0^{\circ}$ (normal incidence) to approximately $58^{\circ}$, the water surface reflectivity is less than $5 \%$.

The reflectivity of a real liquid surface is more complex, however, because it depends on other factors, such as its ripple (waves) and suspended material. Ripple at the surface usually tend to cause the reflected radiation to be scattered in all directions, but may increase reflectivity at low angles of incidence. Additionally, the degree of polarization of light varies throughout the day tending to be higher in the early morning and late afternoon, so that the reflectivity may change at these times.

Anyway, the albedo of the soil is, in general, considered in the range between $15 \%$ and $30 \%$. According to Fig. 5, the water reflectivity may only be higher than this value for solar angles of incidence above $70^{\circ}$, so that this factor could contribute significantly to increasing irradiance on a floating PV array only in places of high latitudes (lower position of sun in the sky), which is not the case of Brazil.

On the other hand, it is also known that the composition and amount of the suspended material in the water may increase the surface albedo, which could be the case in the North region of Brazil, but this is a factor whose significance for the increase in radiation incidence on the array could only be quantified on a case-by-case basis.

\section{Additional Considerations about Floating PV Systems in Brazil}

In Brazil, some additional questions and considerations concerning the floating PV systems must be raised, which are listed below.

(1) Endurance to environmental factors

According to the manufacturer, the "Hydrelio (C)" floating mounting system, adopted in Japan, is expected to be resistant to UV radiation for more than 20 years. We understand, however, that this is still to be proved in tropical regions, with higher incidences of solar radiation (and higher UV index) and higher ambient temperatures.

In addition, by observing available photos, it can be noticed that floating PV systems in other countries have been deployed in lakes with clear water, free of suspended material and of floating debris. In many cases in Brazil, particularly in the North region (Amazon region), the operating conditions can be quite different: water with presence of suspended material (earth/clay), as well as floating material such as branches and leaves, and even floating trunks (logs). There is even a Portuguese word-“balseiros"- to refer to the floating clusters of leaves, branches, soil, grass etc., which descend the rivers during the flood season in the Amazon region. The consequences of this factor should be investigated and probably imply in greater needs for cleaning and maintenance of the floating PV array, and even the need of devices called "floating booms" installed around the floating PV arrays to avoid damages. The so called "floating booms" are floating barriers sometimes used to protect the water intake of hydro power plants from debris in the water.

Still according to the manufacturer, the floating structure "Hydrelio (C)" withstands wind speeds of up to $118 \mathrm{mph}(\sim 52.8 \mathrm{~m} / \mathrm{s})$. We understand that the manufacturer ensures that the structure is not damaged by this worst wind condition. However, we believe that the structure would be partially submerged due to strong frontal winds, so that photovoltaic modules and other components must be resistant to this submersion condition. In addition, it is important to clarify that wind resistance does not depend only on the floating structure itself, but mainly on its anchoring (mooring) system. In the project, one should consider the highest known wind speed in the area, but it should be remembered that these parameters are measured in ground meteorological stations. It is known that the wind speed of a given site is a function of the surface roughness, so that on large liquid surfaces, it can reach higher values than on the ground. Thus, for sizing 
purposes, there shall be considered the use of some mathematical model in order to compute the wind velocity over the liquid surface, based on the highest known wind velocity in the nearby land area.

On the other hand, Choi [13] has already verified that the floating structure can be moved and spinned by the wind, and, mainly, that this movement can have a significant effect on the generation efficiency, concluding that the development of new anchoring systems is necessary.

In Brazil, water reservoirs of hydro power plants can reach extremely low water levels. Sobradinho reservoir, for instance, was operating close to the minimum acceptable volume in November 2015. Therefore, in Brazil the anchoring system should be designed expecting large reservoir water level variations throughout the year. It cannot be ruled out that the floating mounting structure should withstand resting on the bottom (possibly irregular) of a dry reservoir.

It is also well known that, even in the North region (Amazon), the variation of the area occupied by the reservoir between the flood season and the dry season is quite significant, and this is the case of the Balbina reservoir.

Another concern in Brazil is the wave height in the reservoirs, which is a function of not only the wind speed, but also of its extensions. The lake of Balbina has an extension of $225 \mathrm{~km}$ and Sobradinho has 350 $\mathrm{km}$, what can imply in wave heights higher than those verified in the reservoirs with floating plants in other countries, that the floating structures and anchoring systems must resist.

\section{(2) Installation and maintenance costs}

According to Ref. [18], the installation cost of a floating PV system of 1.2 MWp was 30\% higher than that of a conventional system, but it warns that this value is probably due to being the first of this size installed. According to Ref. [7], in the USA, floating systems with installed power above $10 \mathrm{MWp}$ would have a cost similar to conventional installations on the ground. Lee [8] informs that the $100 \mathrm{kWp}$ floating plant built at Hapcheon (South Korea) had a cost of US\$ 6.4/Wp, but the bigger installation of $500 \mathrm{kWp}$ at the same place reached US\$ $4.35 / \mathrm{Wp}$ due to improvements.

Components such as submersible cables, waterproof PV modules and junction boxes that are resistant to submersion of course have higher costs than conventional ones.

The installation of the system is also more difficult and costly. Apparently, this extra cost is offset by the fact that the system does not use land, which results in a cost reduction. As aforementioned, this cost advantage is not necessarily valid in Brazil, depending on the area of the country where the installation will be deployed.

The maintenance cost of a floating system is also clearly higher than that of conventional systems, since access to the PV array is much more difficult and depends on the availability of motorboats and technical personnel able to operate them.

(3) Environmental impacts

The literature generally states that floating PV systems have low environmental impact and do not impair the cleanliness of water, although the issue of algae growth reduction, already mentioned, may represent an environmental impact that can be significant if a large fraction of the free water surface of the reservoir is covered by the floating PV array. In this respect, in Brazil it is strongly advisable that the PV array has the maximum possible light transmittance, which can be achieved by adopting PV modules of glass-glass type (glass on the back surface).

In addition, Solaris [19] raises the question related to the oxygenation of the water body, stating that the gas exchange at the water surface must be investigated in order to assure the maintenance of the lake fauna and flora, suggesting that covering a large portion of the surface by a PV array can represent an important impact also in this respect. Reduction of oxygenation can even increase greenhouse gas emissions from the reservoir.

On the other hand, an indirect and beneficial 
environmental impact of the floating PV plant is that it can avoid deforestation, what sometimes can be necessary in order to build a conventional PV installation on the ground.

\section{Conclusions}

This paper presents several considerations regarding the application of floating PV plants in Brazil, whose peculiarities make them different from those that have been deployed in other places, such as Japan and Korea, for example, and are summarized below:

- It is estimated that the increase in the efficiency of the floating PV plant due to evaporative cooling may be significant in the Northeast region of the country (Sobradinho reservoir), but not significant in the North region (Balbina reservoir);

- The beneficial effect of reducing water loss by evaporation from the reservoirs depends on the fraction of area covered. It will be very different in different locations in Brazil, and needs to be better quantified;

- The combined operation of the PV and hydro plants is not considered feasible, but may be a topic for R\&D, perhaps associated to an energy storage system;

- The sharing of the existing transmission infrastructure is probably the biggest advantage of the floating PV plants to be deployed in Brazil in reservoirs of hydro power plants;

- Large scale floating PV plants can have a significant environmental impact by reducing algae growth and water oxygenation, and to minimize the first effect, glass-glass photovoltaic modules shall be used in Brazil;

- The resistance of PV array floating mountings to conditions of solar radiation and temperature in tropical regions, as well as to water with suspended material and floating debris must be ensured in Brazil;

- The floating structure and its anchoring system must withstand large variations in the water level, including the possibility of resting on the bottom of a dry reservoir. High wave heights are also to be expected;
- Since the costs of installation, maintenance for floating PVPs are higher than conventional plants, the technical and economic advantages of such floating systems over conventional PV installations are not yet clear in Brazil and will be different for each region. The main economic advantage in Brazil seems to be the sharing of the existing transmission infrastructure.

Considering the aforementioned issues, it is expected that the pilot project of floating PV to be deployed in the Balbina and Sobradinho reservoirs will provide important clarifications, mainly in relation to efficiency issues, compared to a system installed on the ground and reduction of evaporative losses in the reservoir. An environmental assessment regarding items such as light incidence in water, algae growth and oxygenation should also be performed. To do so, these systems must be fully monitored by means of a set of sensors, including electrical and environmental quantities, allowing to evaluate such parameters.

\section{References}

[1] Colthorpe, A. 2015. "Another Floating PV Plant Completed by Kyocera JV in Japan.” May 28th, 2015. http://www.pv-tech.org/news/another_floating_pv_plant_ completed_by_kyocera_jv_in_japan.

[2] Owano, N. 2015. "Japan Has Floating Solar Power Plants in Hyogo Prefecture.” April 24th, 2015. http://techxplore.com/news/2015-04-japan-solar-power-h yogo-prefecture.html.

[3] Upadhyay, A. 2015a. "Kyocera TCL Solar Completes Two Floating Solar Power Plants In Japan.” April 27th, 2015.

http://cleantechnica.com/2015/04/27/kyocera-tcl-solar-co mpletes-two-floating-solar-power-plants-japan/.

[4] Upadhyay, A. 2014. "World's Largest Floating Solar Power Plant Announced by Kyocera.” December 25th, 2014.

http://cleantechnica.com/2014/12/25/worlds-largest-floati ng-solar-power-plant-announced-kyocera/.

[5] Japan Times. 2014. http://www.japantimes.co.jp/news/2014/12/23/business/k yocera-to-build-13-4-megawatt-floating-solar-power-plan t-near-tokyo/\#.Vlm0dHbnuUk.

[6] Osborne M. 2014. “SolarPark Korea’s PV Modules Used in Floating Tracker Power Plant.” December 12th, 2014. http://www.pv-tech.org/news/solarpark_koreas_pv_modu les_used_in_floating_tracker_power_plant. 
[7] Pyper, J. 2015. "Sonoma County Is Building the Largest Floating Solar Project in the US.” March 11th, 2015. http://www.greentechmedia.com/articles/read/sonoma-co unty-to-build-the-largest-floating-solar-project-in-the-us.

[8] Lee, D.-H. 2015. "New Technology of the Floating Photovoltaic Power Plant on the Reservoirs of Dams." April, $\quad$ 14th, 2015. https://www.kwater.or.kr/web/download/forum/09-1_PS.pdf.

[9] Gandra, A. 2015. "Projeto-piloto de geração de energia solar em reservatórios começa em 120 dias.” March, 27th, $2015 . \quad$ Agência Brasil. http://agenciabrasil.ebc.com.br/economia/noticia/2015-03 /projeto-piloto-de-geracao-de-energia-solar-em-reservator ios-comeca-em-120.

[10] Clark, L. 2015. “'Mega’ Floating Solar Power Plants Open in Japan.” April 21st 2015. http://www.wired.co.uk/news/archive/2015-04/21/giant-fl oating-solar-panel-plant-japan.

[11] Upadhyay, A. 2015b. "Brazil Announces Huge 350 MW Floating Solar Power Plant.” April 6th, 2015. http://cleantechnica.com/2015/04/06/brazil-announces-hu ge-350-mw-floating-solar-power-plant/.

[12] SP. 2016. Secretaria de Energia e Mineração, Governo do Estado de São Paulo. "São Paulo coloca em operação a primeira usina solar flutuante do Brasil.” 29/09/2016. http://www.energia.sp.gov.br/2016/09/sao-paulo-coloca-e m-operacao-primeira-usina-solar-flutuante-do-brasil/.

[13] Choi, Y.-K. 2013. "A Study on Power Generation
Analysis of Floating PV System Considering Environmental Impact.” International Journal of Software Engineering and Its Applications 8 (1): 75-84. http://dx.doi.org/10.14257/ijseia.2014.8.1.07.

[14] ONS-Operador Nacional do Sistema Elétrico. 2015. "Inventário de Dados Técnicos de Aproveitamentos Hidroelétricos.”

http://www.ons.org.br/operacao/hidrologia.aspx.

[15] Eletrobras, GTON-Grupo Técnico Operacional da Região Norte. 2013. "Plano Anual de Operação dos Sistemas Isolados para 2013.” Versão 1.0. 19/11/2012.

[16] Galdino, M. A. E., and Gomes, C. M. 1996. "SUNDATA 2.0. Brazilian Solar Resource Database.” Cepel—Electric Power Research Center. Cresesb-Centro de Referência para Energia Solar e Eólica Sérgio de Salvo Brito. http://www.cresesb.cepel.br/index.php?section=sundata.

[17] Colthorpe, A. 2014. "Kyocera Sees Floating PV as One Solution to Japan Land Shortages.” September 1st, 2014. http://www.pv-tech.org/news/kyocera_sees_floating_pv_ as_solution_to_japan_land_shortages.

[18] Kato, S. 2013. “'World's Largest’ Floating Solar Plant Operates on Reservoir.” November, 17th, 2013. http://techon.nikkeibp.co.jp/english/NEWS_EN/2013111 7/316700/\#.

[19] Solaris. 2015. Information about the floating PV plant to be installed by the company Solaris Synergy Ltd. at Cadarache (France). Consulted in June, 2015. http://www.eurekanetwork.org/content/e-5044-aquasun. 